\title{
Original Article \\ CONSULTATION LIAISON PSYCHIATRY - DIAGNOSTIC CONCORDANCE BETWEEN REFERRING PHYSICIAN AND PSYCHIATRIST
}

Keerthy Reji ${ }^{1}$, Sivin P Sam ${ }^{1}$, Soumya P Thomas ${ }^{1}$, Sheena Varughese ${ }^{1}$, Joice Geo ${ }^{1}$, Vijayalal Vijayan ${ }^{1}$, Roy Abraham Kallivayali1 ${ }^{1 *}$

'Department of Psychiatry, Pushpagiri Medical College, Thiruvalla

*Correspondence Address: roykalli@gmail.com

First Submitted on: 10/1/2020

Published Online:21/2/2020

\begin{abstract}
Background: Consultation - liaison psychiatry (CLP) provides expert advice and act as a liaison. There is a high prevalence of psychiatric comorbidities among patients of other specialities. Yet, the referral rates are low, probably due to inadequate psychiatric awareness which can be assessed from the diagnostic concordance.

Objective: To assess diagnostic concordance between the psychiatrist and referring doctor.

Materials and Methods: This is a cross-sectional record-based study of all inpatients referred to CLP. Data was collected from CLP registry.

Results: Most of the referrals were from General Medicine. The most common reason for referral was alcohol use disorders and common diagnoses made by referring physicians were alcohol use disorders, delirium and mood disorders, similar to the psychiatrist's diagnoses; however, deliberate self harm (DSH), a common diagnosis made by the referring doctor, constituted only $4.2 \%$ of psychiatrist's diagnoses. There was complete diagnostic concordance for $40.9 \%$; perfect agreement was found for DSH and alcohol use disorders, substantial agreement for delirium and moderate agreement for mood disorders. The agreement was low for DSH with comorbid depression, other substance use disorders and organic mental disorders.

Conclusion: The diagnostic concordance for common mental health problems is low, according to the present study. CLP needs to extend its educational function towards other specialities, and it should be an active component of undergraduate psychiatric training.
\end{abstract}

Keywords: Consultation Liaison Psychiatry, Diagnostic concordance

Please cite the article as: Keerthy R, Sivin P S, Soumya P, Sheena V, Joice G, Vijayalal V, Kallivayalil RA Consultation liaison psychiatry - diagnostic concordance between referring physician and psychiatrist. Kerala Tournal of Psychiatry 2020;33(1): 16-26. doi: 10.30834/K IP.33.1.2020.182 


\section{INTRODUCTION}

Consultation-Liaison is a subspecialty of psychiatry that deals with providing an expert psychiatric opinion in the management of patients referred to psychiatry from other medical and surgical specialities. It studies, practices and teaches the interrelation between psychiatric and medical disorders. ${ }^{1}$ Its primary role is giving expert advice on the management of psychiatric aspects of the patient's illness in order to provide holistic care. However, another important function that mustn't be overlooked is its liaison function where it acts as a link. It denotes the educational role which must extend to the patient and family as well as the primary treating team and other counterparts of health care providers. ${ }^{2}$ They must be educated about the need for timely recognition of psychiatric symptoms and accessing the consultation services. Studies have shown that timely psychiatric intervention helps to reduce hospital stay, morbidity and mortality of patients. ${ }^{3-5}$

Psychiatric comorbidities among patients of another department have been found to be high. Studies from India have reported psychiatric comorbidities of $31-34.5 \%$ among inpatients $^{6}$ and 18.32-53.7\% $\%^{7-10}$ among outpatients of other departments. Psychiatric referral rates of $0.06-3.6 \%$ as per previous studies are however not at par with this prevalence. ${ }^{6}$ The reasons for this relatively low referral rate can be; focusing primarily on physical health, ${ }^{2}$ difficulty in detecting psychiatric symptoms, a negative attitude towards psychiatry among patients and health care providers, and patient and family refusal due to the stigma involved. The difficulty in detection can be a reflection of poor psychiatric awareness due to inadequate undergraduate level psychiatric training which may be due to insufficiency in the current medical curriculum. ${ }^{2}$ Studying the concordance between psychiatric diagnosis made by the referring doctor and psychiatrist can provide more light in this area. Ours is the first study from Kerala, and perhaps even from South India, to assess the concordance of the psychiatric diagnosis made by the referring physician (if conveyed) with the final diagnosis made by the psychiatrist. If concordant, it may suggest the achievement of consultation-liaison psychiatry (CLP) as an educational link.

Though there are many Indian and International studies on consultation-liaison psychiatry, only a few studies have ventured in assessing the concordance between diagnosis made by the primary treating team and final psychiatric diagnosis. Grover et al. found a complete diagnostic match in a quarter of the sample they studied among inpatients in North India. ${ }^{2}$ Concordance was found to be low for common disorders like delirium and depression but there was good concordance for Substance dependence and self-harm. ${ }^{2}$ Studies from other countries reported a concordance of $41.5 \%$ to $47.4 \%$ between diagnoses made by physician and psychiatrist. ${ }^{11-13}$ A study on elderly from Japan assessed concordance using kappa statistics and found 0.47 concordance for $\mathrm{F} 0$, 0.27 for F1, 0.25 for F2 and 3, 0.32 for F 4 and 5 ICD diagnoses. ${ }^{12}$ Among 23 cases diagnosed as depression by the physician; the psychiatrist diagnosed 12 cases as delirium and 4 cases as Psychoactive substance use disorder. ${ }^{12}$ Another study reported that rather than psychotic, cognitive and emotional symptoms, doctors of other specialities were 
better able to detect negative symptoms, conversion disorders, and DSH. ${ }^{14}$ One study found high accuracy of the diagnosis of cognitive (100\%) and substance use disorders (88\%) by physicians but comparatively low accuracy for depressive disorders (53.6\%). ${ }^{15}$ Another study from KSA found highest accuracy for cognitive disorders (60\%) followed by depression (50\%) and zero accuracy was found for psychosis. $^{16}$ Yet another study found that misdiagnosis of cognitive disorders is common, mistaking them for another psychiatric diagnosis like depression. $^{11}$

There have been many studies on the reasons for referral in India. A study from North India ${ }^{2}$ reported that a specific diagnosis was mentioned as the reason for referral in 57\% cases referred to them, most common diagnoses being Depression (13.7\%) and Substance abuse (13.2\%) followed by Delirium (11.4\%) and Psychosis (7.8\%). Symptoms were mentioned as a reason in 28.8\% cases, most common being irrelevant talk, suicidal behaviour, agitation and aggression, altered sensorium, disorientation, irritability, abnormal behaviour and functional pain. $5.5 \%$ of patients were referred to as they were 'known case of psychiatric illnesses, $4.6 \%$ for clearance for surgery and $4.1 \%$ to rule out psychiatric illness. ${ }^{2} \mathrm{~A}$ study from South India found the most common reason for referral to be the evaluation of comorbid psychiatric illness (32.6\%), followed by DSH (30.3\%), medically unexplained somatic symptoms (19.3\%), past psychiatric history and substance use-related problems. ${ }^{17}$ Another study reported most common reasons for referral to be altered sensorium and behavioural problems (21.65\%), alcohol dependence (18.47\%) and depression (16.5\%), past $\mathrm{h} / \mathrm{o}$ psychiatric illness $(28.6 \%){ }^{8}$

The most common diagnosis made by the psychiatrist as reported by a study in North India was delirium in $43.4 \%$, depression in $11.9 \%$ and alcohol dependence in $7.3 \%$ but no psychiatric diagnosis was made in $11.4 \%$ referrals. $^{2}$ Another study had similar findings. ${ }^{18}$ A study from South India found organic mental disorders to be the most common psychiatric diagnosis followed by neurotic, stress-related and somatoform disorders, and then, affective and substance use disorders. ${ }^{17} \mathrm{~A}$ study from another tertiary care centre in South India had similar findings except for Organic mental disorders. ${ }^{19}$

The commonest source of referrals in most studies were General Medicine department and most other referrals were from Neuromedicine, Emergency departments, General Surgery, Obstetrics and Gynecology, Orthopedics and Dermatology. ${ }^{10,17-19}$ A study from North India also reported $7.64 \%$ of their sample was referred from intensive care units (ICUs). ${ }^{18}$

In this context, the study is planned to assess the diagnostic concordance between psychiatrist and referring doctor among referrals made to the psychiatric consultationliaison team. It was also planned to find common reasons for referral to CL psychiatry team.

\section{METHODOLOGY}

Study Design: A cross-sectional record-based study was conducted among in-patients referred from other specialities to consultation liaison unit of Psychiatry department of a tertiary care centre in Kerala. 
Study Setting: Consultation liaison unit of our Psychiatry department functions as a 2tier system where, on receiving referral call through consultation slips, the referred patients are first evaluated by a trainee psychiatrist posted in the consultation-liaison team and then by a consultant psychiatrist. The final diagnosis, along with the treatment plan, is then conveyed to the primary treating team.

Study Duration: One year from August 2017 to July 2018.

Eligibility Criteria: All inpatients referred were included in the study, but reviews were excluded unless referral was for a different reason.

Methods of data collection- The sociodemographic data of patients (age, gender, education, and occupation), specific psychiatric diagnoses if conveyed and the reasons for referral, source of referral and the psychiatrist's final diagnoses were collected from the consultation registry which was then analyzed with appropriate statistical tools.

Statistical Data Analysis: The data was analyzed, and the categorical variables were presented as frequencies and percentages. Age was presented as mean, standard deviation and range and then grouped into suitable intervals. Agreement between Referring doctor's diagnosis and the diagnosis made by the Psychiatrist was done using Kappa statistics for each of the diagnosis. The Kappa was interpreted based on the criteria by Landis and Koch. ${ }^{20}$

\section{RESULTS}

There was a total of 766 referrals to consultation liaison psychiatry. Of this, 530 referrals, excluding the reviews, were considered for the study. There were 30189 inpatients (IP) in the hospital excluding psychiatry inpatients of 755 , in the time period from August 2017 to July 2018. The referral rate calculated was $1.76 \%$.

Age of the study sample ranged from 7 to 100 years, the majority were in the age group 4564 years, and the mean (SD) age was 54.24 years (18.71). 59.6\% of the sample studied were males, and $82.7 \%$ had at least secondary education of which, 38.2\% had senior secondary education or above. Only two patients were illiterate in the study, and only $7.2 \%$ were unemployed.

Table.1. Source of Referrals

\begin{tabular}{|l|l|}
\hline Speciality & $\%$ \\
\hline General Medicine & 36.4 \\
\hline Critical Care & 14.2 \\
\hline Gastroenterology & 10.2 \\
\hline General Surgery & 7.7 \\
\hline Neuro Medicine & 7 \\
\hline Orthopaedics & 6.2 \\
\hline Neurosurgery & 4.2 \\
\hline Nephrology & 3.4 \\
\hline Cardiology & 3.2 \\
\hline Others & 7.3 \\
\hline
\end{tabular}


Table.2. Reasons for Referral

\begin{tabular}{|l|c|c|}
\hline Reasons & Frequency & Per cent $^{*}$ \\
\hline Alcohol related problems & 140 & 26.4 \\
\hline Non-specific behavioural symptoms & 119 & 22.6 \\
\hline Psychiatric illness for follow-up & 100 & 18.9 \\
\hline DSH & 48 & 9.1 \\
\hline Depressive symptoms & 45 & 8.5 \\
\hline Disorientation & 41 & 7.7 \\
\hline Somatic complaints & 20 & 3.8 \\
\hline Psychotic symptoms & 20 & 3.8 \\
\hline Anxiety symptoms & 8 & 1.6 \\
\hline For breaking bad news /Counseling for adjustment issues & 6 & 1.1 \\
\hline Mixed Anxiety and depressive symptoms & 4 & 0.8 \\
\hline Surgery clearance & 1 & 0.2 \\
\hline Catatonia & 6.2 \\
\hline Excessive video gaming & 43 & \\
\hline
\end{tabular}

*Sum of percentages is more than 100 due to multiple reasons for individual patients

Most of the referrals were from General medicine department (36.4\%) followed by Critical care department, Gastroenterology, Surgery, Neuro Medicine, Orthopedics, Neurosurgery, Nephrology and Cardiology. Low referrals were from Pediatrics, Plastic surgery, ENT, Dermatology, CVTS, Urology and Pain and Palliative. (Table.1)

The most common reason for referral was found to be Alcohol use disorders (26.4\%). Other common reasons were nonspecific behavioural problems (like anger, restlessness, agitation, irrelevant talk), psychiatric illness for follow up, self-harm, depressive symptoms, disorientation and somatic complaints, psychotic symptoms and anxiety symptoms (Table 2). For $1.7 \%$ of cases, no reasons were mentioned for the referral. There were 146 ICU referrals, common reasons being Alcohol withdrawal, including delirium and seizures, Bipolar Affective disorder (BPAD), delirium due to other causes and previous psychiatric illness.

Out of the 530 referrals, the psychiatric diagnosis was suggested by the physician for 315 patients. Common diagnoses considered 
Table.3. Comparison Between Referring Doctor's and Psychiatrist's Diagnosis, and Concordance

\begin{tabular}{|c|c|c|c|c|}
\hline \multirow[t]{2}{*}{ Diagnosis } & \multirow{2}{*}{$\begin{array}{c}\text { Physician } \\
\begin{array}{c}\text { Frequency } \\
(\%)\end{array}\end{array}$} & \multirow{2}{*}{$\begin{array}{c}\text { Psychiatrist } \\
\text { Frequency (\%) }\end{array}$} & \multicolumn{2}{|c|}{ Concordance (Kappa Values) } \\
\hline & & & $\mathrm{k}$ & Agreement \\
\hline Delirium & $35(6.6)$ & $82(15.5)$ & 0.751 & Substantial \\
\hline Dementia & $2(0.4)$ & $13(2.5)$ & 0.112 & Slight \\
\hline Other Organic mental disorder & $2(0.4)$ & $22(4.2)$ & -0.007 & Poor \\
\hline Alcohol use disorders & $140(26.4)$ & $146(26.9)$ & 0.877 & Almost Perfect \\
\hline Other substance use & - & $8(1.5)$ & 0.0 & Poor \\
\hline Schizophrenia* & $4(0.8)$ & $12(2.3)$ & 0.213 & Fair \\
\hline Delusional disorder* & $3(0.6)$ & $7(1.3)$ & 0.302 & Fair \\
\hline Acute and transient psychotic disorder & $2(0.4)$ & $3(0.6)$ & 0.397 & Fair \\
\hline Unspecified Psychosis & $4(0.8)$ & $27(5.1)$ & -0.016 & Poor \\
\hline BPAD & $19(3.6)$ & $55(10.4)$ & 0.444 & Moderate \\
\hline Depressive disorders & $18(3.4)$ & $59(11.1)$ & 0.58 & Moderate \\
\hline Anxiety disorder & $16(1.9)$ & $15(2.9)$ & 0.403 & Fair \\
\hline PTSD & $4(0.8)$ & $2(0.4)$ & 0.33 & Fair \\
\hline Acute stress reaction & - & $3(0.6)$ & 0.0 & Poor \\
\hline Adjustment disorders & - & $37(7.0)$ & 0.0 & Poor \\
\hline Conversion disorders & $7(1.3)$ & $9(1.7)$ & 0.223 & Fair \\
\hline Somatoform disorders & $3(0.6)$ & $5(1.0)$ & 0.33 & Fair \\
\hline Anorexia Nervosa & $7(1.3)$ & $1(0.2)$ & -0.002 & Poor \\
\hline Insomnia & $4(0.8)$ & $1(0.2)$ & -0.003 & Poor \\
\hline Personality disorder & $1(0.2)$ & $13(2.5)$ & 0.179 & Slight \\
\hline Factitious disorder & - & $1(0.2)$ & 0.0 & Poor \\
\hline
\end{tabular}

*The sum of percentages is more than 100 due to multiple diagnoses for individual patients 
Table.3. Comparison Between Referring Doctor's and Psychiatrist's Diagnosis, and Concordance (Continued)

\begin{tabular}{|c|c|c|c|c|}
\hline \multirow[t]{2}{*}{ Diagnosis } & \multirow{2}{*}{$\begin{array}{l}\text { Physician } \\
\text { Frequency (\%) }\end{array}$} & \multirow{2}{*}{$\begin{array}{l}\text { Psychiatrist } \\
\text { Frequency (\%) }\end{array}$} & \multicolumn{2}{|c|}{ Concordance (Kappa Values) } \\
\hline & & & $\mathrm{k}$ & Agreement \\
\hline Mental Retardation & $5(0.9)$ & $8(1.5)$ & 0.566 & Moderate \\
\hline ADHD & $1(0.2)$ & $2(0.4)$ & 0.666 & Substantial \\
\hline Neuroleptic malignant syndrome & $2(0.4)$ & $2(0.4)$ & 0.498 & Moderate \\
\hline Lithium toxicity & - & $1(0.2)$ & 0.0 & Poor \\
\hline Amnesia & $1(0.2)$ & - & - & \\
\hline DSH & $48(9.1)$ & $48(9.2)$ & 1 & Almost Perfect \\
\hline DSH+ Depression & 1 & 12 & 0.151 & Slight \\
\hline $\mathrm{DSH}+\mathrm{BPAD}$ & & 5 & - & \\
\hline $\mathrm{DSH}+\mathrm{ADS}$ & 1 & 3 & 0.33 & Fair \\
\hline DSH+ Personality disorder & & 6 & - & \\
\hline DSH+ Psychosis & & 4 & - & \\
\hline $\mathrm{DSH}+$ Adjustment $\mathrm{D} / \mathrm{o}$ & & 18 & - & \\
\hline No Diagnosis & $215(40.6)$ & & & \\
\hline No active psychiatric illness diagnosed & - & $24(4.5)$ & & \\
\hline
\end{tabular}

${ }^{*}$ The sum of percentages is more than 100 due to multiple diagnoses for individual patients

by referring physicians/surgeons were Alcohol use disorders, Deliberate self-harm, Delirium, BPAD, Depression, Anxiety disorders, and Conversion disorders. No diagnosis was conveyed for 215 patients (Table 3).

Diagnoses made by the psychiatrist were mostly Alcohol-related disorders, Delirium, Depressive disorder, BPAD, Adjustment disorder, Unspecified psychosis, other Organic mental disorders (Table.3).

Complete diagnostic match between physician and psychiatrist were obtained for 217 diagnoses (40.9\%). Kappa Values obtained were 1 and 0.877 for DSH and Alcohol use disorders, i.e., almost perfect agreement. There was a moderate agreement for Delirium, Attention deficit hyperactivity disorder, Depressive disorder, Mental retardation and BPAD. A fair agreement was obtained for Schizophrenia, delusional disorder, Acute and transient psychotic disorder, Anxiety disorder, Somatoform and Conversion disorders while other diagnoses had either slight or poor agreement. Physicians did not attempt to diagnose any comorbid psychopathology in DSH attempters in most cases (Tables 3 and 4) 
Table No.4- Diagnostic concordance (Kappa statistics)

\begin{tabular}{|c|c|}
\hline \multicolumn{2}{|c|}{ Complete Diagnostic match was obtained for 217 diagnoses (40.9\%) } \\
\hline $\begin{array}{l}\frac{\text { Good (Almost perfect }+ \text { Substantial }}{\text { Agreement) }} \\
\begin{array}{ll}\text { 1. Alcohol use disorders } \\
\text { 2. Delirium } \\
\text { 3. ADHD }\end{array}\end{array}$ & $\begin{array}{cl}\text { Moderate (Moderate Agreement) } \\
\text { 1. } & \text { Depressive disorder } \\
\text { 2. } & \text { Bipolar affective disorder } \\
\text { 3. } & \text { Mental retardation }\end{array}$ \\
\hline $\begin{array}{ll}\text { Fair }(\text { Fair Agreement) } \\
\text { 1. } & \text { Anxiety disorder } \\
\text { 2. } & \text { Acute psychosis } \\
\text { 3. } & \text { Delusional disorder } \\
\text { 4. } & \text { Schizophrenia } \\
\text { 5. } & \text { Conversion disorder } \\
\text { 6. } & \text { Somatoform disorder } \\
\text { 7. } & \text { PTSD }\end{array}$ & $\begin{array}{l}\text { Poor (Slight }+ \text { Poor agreement) } \\
\text { 1. Dementia } \\
\text { 2. DSH + Depression / other comorbidities } \\
\text { 3. Other Organic mental disorder } \\
\text { 4. Other substance abuse } \\
\text { 5. Acute Stress reaction } \\
\text { 6. Adjustment disorder } \\
\text { 7. Anorexia Nervosa } \\
\text { 8. Insomnia } \\
\text { 9. Factitious Disorder }\end{array}$ \\
\hline
\end{tabular}

\section{DISCUSSION}

The referral rate of $1.76 \%$ obtained is comparable to findings of previous studies $(0.15-3.6 \%),{ }^{2,6}$ but it is deficient compared to the prevalence of psychiatric comorbidities: $31-34.5 \%$ among inpatients and $18.32-53.7 \%{ }^{6-}$ ${ }^{10}$ in outpatients of other departments. The mean age was higher compared to other studies ${ }^{2,17-19,21}$ and may be attributed to the high life expectancy, and literacy rate of Kerala. ${ }^{22}$ Majority were males which is similar to previous study findings ${ }^{2,17-19,21}$, and the majority had at least secondary education similar to other studies. ${ }^{18}$ Major occupations were either professional or skilled work which might be a contributing factor in reducing the stigma involved and reflect the productivity undeterred by the illness. Housewives were another part of the majority and should not be overlooked in screening for psychiatric illnesses, keeping in mind, the possibility of multiple stressors. Most common sources of referral were General Medicine followed by Critical Care, Gastroenterology, General Surgery, Neuromedicine and orthopaedics departments, all comparable to previous studies. ${ }^{2,17-19}$ The referrals were lowest $(0.2 \%)$ from Pain and palliative, which is low compared to the prevalence of psychiatric disorders of $41.7 \%$ among cancer patients found in a study from Kerala. ${ }^{23}$ But low referrals from Pain and palliative and other super speciality departments can also be due to the larger bed strength in General medical and surgical departments and a pain and palliative clinic collaboratively run by departments of Psychiatry and Pain and Palliative care.

The most common reason for referral, psychiatric diagnosis made by the physician and the psychiatrist's final diagnosis were Alcohol use disorders (25.3, 26.4 and 26.9\% 
respectively). This finding is in accordance with findings of Patra et al. ${ }^{18}$ but contrary to other studies. ${ }^{2,17,19}$ and may be due to the increasing prevalence of Alcohol use disorders. But it might also be due to a high referral rate from Gastroenterology department, which ranked third among the source of referrals. Other substance use disorders were either not considered for referral by physician, while psychiatrist identified them in $1.5 \%$. Among referrals made for past psychiatric illness $16.4 \%$ $(\mathrm{n}=86),{ }^{2,17,19}$ no active symptoms were mentioned in $14.7 \%$, and no specific past diagnosis was mentioned in 50 cases, which may be availed from old records, reflecting a lesser focus on mental health. Referrals for altered behaviour, self-harm, disorientation and psychogenic somatic complaints were common similar to previous studies. ${ }^{2}$ Referrals for evaluation of non-specific behavioural symptoms (22.6\%), breaking bad news and psychotherapy (1.6\%) is more compared to other studies ${ }^{2}$, which suggests better receptiveness to psychiatry.

DSH was the second commonest diagnosis made by the physician, but they failed to recognize comorbid condition which was recognized by psychiatrist like Depressive disorder( $\mathrm{n}=12), \quad \operatorname{BPAD}(\mathrm{n}=5) \quad$ Adjustment disorder $(n=18)$, Personality disorder $(n=6)$, Psychosis $(n=4)$ and Alcohol use disorders $(n=3)$. Meanwhile, the physician recognized only one DSH patient with underlying depression and one with Alcohol use disorders. This may reflect poor psychiatric awareness among other specialities. Only $6.6 \%$ were diagnosed as delirium by the physician while psychiatrist diagnosed delirium in $15.5 \%$. This difference was partly due to misdiagnosis of $0.9 \%$
Delirium as Depression, BPAD, Insomnia and Dementia as in older studies ${ }^{10}$ and partly due to remaining unidentified by the physician. Diagnoses of BPAD, Depressive disorder and Anxiety disorder were low as in previous studies, $27-19$ where physiciandiagnosed 3.6, 3.4 and $1.9 \%$ respectively while psychiatrist diagnosed $10.4,11.1$ and $2.9 \%$ though they warrant prompt identification and intervention.

$40.9 \%$ showed a complete diagnostic match between the physician's and psychiatrist's diagnosis, which is more than the $24.65 \%$ reported in a study from North India, ${ }^{10}$ but comparable to studies from other countries. ${ }^{13} \mathrm{Almost}$ perfect agreement between physician's and psychiatrist's diagnosis was obtained only for DSH and alcohol use disorders, probably owing to ease of identification. But other substance use disorders had poor concordance suggesting less focus given to them. Many cases of delirium were misdiagnosed as depression, BPAD, etc. but still there was substantial agreement. Mixed anxiety and depressive disorder and ADHD also showed substantial agreement. However, disorders warranting prompt help like depression, and BPAD had only moderate agreement. MR also had moderate agreement while anxiety disorders, schizophrenia, ATPD, delusional disorders, conversion disorders, somatoform disorders, PTSD, DSH with comorbid alcohol use had only fair agreement. Comorbid depression in DSH attempters, a serious mental health issue, was often overlooked by the primary team which must be the reason for only the slight agreement. Dementia in contrast to previous studies ${ }^{13}$ and Personality disorder also showed only slight agreement. When Physicians diagnosed only $0.8 \%$ of organic 
mental disorders other than dementia, Psychiatrists recognized $6.7 \%$ and concordance was poor between both diagnoses. Other substance use, Acute stress reaction, adjustment disorder, factitious disorders, Anorexia nervosa, Insomnia had a poor agreement.

This low diagnostic concordance for even common psychiatric illness is probably because CLP was not able to provide adequate psychiatric training to the referring physicians and surgeons, which must have been initiated at the undergraduate level, despite whatever growth CLP was able to accomplish till now. It requires the liaison role to be implemented more seriously and drastically so that often 'unseen' patients needing psychiatric help will be identified and provided care.

\section{CONCLUSIONS}

The diagnostic concordance for common mental health problems is low, as found in the present study. Low concordance for BPAD, depression, other substance use disorders and failure to identify psychiatric comorbidities in DSH attempters require serious notice. CLP needs to focus on its educational role which is best initiated at the undergraduate level as well as extend it to other specialities which can be achieved by organizing partnered case conferences and other clinical discussions involving both referring team and the CLP team. Current medical curriculum for undergraduate psychiatric training may be inadequate, and psychiatry can be considered to be taught as the main subject since mental health is as important as physical health in providing holistic care: "Mens sana in corpora sano"- A healthy mind in a healthy body.

\section{Limitations and Future Directions}

The study was a cross-sectional study; hence long-term beneficial outcomes of psychiatric consultation couldn't be assessed. OP patients, including patients from the Emergency Department, referred to psychiatry, were not included, and hence the findings cannot be generalized. Considering the limitations, future researches with prospective studies of the referrals, including outpatients, also in the study sample, may be helpful.

\section{Financial support and sponsorship}

Nil.

\section{Conflicts of interest}

There are no conflicts of interest.

\section{REFERENCES}

1. Sadock BJ, Sadock VA. Consultation-liaison psychiatry. Kaplan \& Sadock's Synopsis of Psychiatry. 10th ed. Philadelphia, PA: Lippincott Williams \& Wilkins; 2007. p. 828-38.

2. Grover S, Sahoo S, Aggarwal S, Dhiman S, Chakrabarti S, Avasthi A. Reasons for referral and diagnostic concordance between physicians/surgeons and the consultation-liaison psychiatry team: An exploratory study from a tertiary care hospital in India. Indian journal of psychiatry. $2017 ; 59(2): 170-75$.

3. Wood R, Wand AP, Hunt GE. Relationship between timeliness of contact and length of stay in older and younger patients of a consultationliaison psychiatry service. BJPsych bulletin. 2015;39(3):128-33.

4. Bujoreanu S, White MT, Gerber B, Ibeziako P. Effect of timing of psychiatry consultation on length of pediatric hospitalization and hospital charges. Hospital pediatrics. 2015 ;5(5):269-75.

5. Desan PH, Zimbrean PC, Weinstein AJ, Bozzo JE, Sledge WH. Proactive psychiatric consultation services reduce length of stay for 
admissions to an inpatient medical team. Psychosomatics. 2011;52(6):513-20.

6. Grover S. State of consultation-liaison psychiatry in India: Current status and vision for future. Indian journal of psychiatry. 2011;53(3):202-13.

7. Bhatia MS, Balakrishna NK, Bohra N, Gupta H, Malik SC. Psychiatric morbidity in patients attending medical OPD. Indian journal of psychiatry. 1987;29(3):243-6.

8. Bagadia VN, Ayyar KS, Lakdawala PD, Sheth SM, Acharya VN, Pradhan PV. Psychiatric morbidity among patients attending medical outpatient department. Indian J Psychiatry 1989; 28:139-44.

9. Goyal A, Bhojak MM, Verma KK, Singhal A, Jhirwal OP, Bhojak M. Psychiatric morbidity among patients attending cardiac OPD. Indian J Psychiatry 2001; 43:335-9.

10. Agrawal P, Malik SC, Padubidri V. A study of psychiatric morbidity in gynecology outpatient clinic. Indian Journal of psychiatry. 1990 ;32(1):57-63.

11. Aljarad AM, Al Osaimi FD, Al Huthail YR. Accuracy of psychiatric diagnoses in consultation liaison psychiatry. Journal of Taibah University Medical Sciences. 2008 ;3(2):123-8.

12. Yamada K, Hosoda M, Nakashima S, Furuta K, Awata S. Psychiatric diagnosis in the elderly referred to a consultation-liaison psychiatry service in a general geriatric hospital in Japan. Geriatrics \& gerontology international. 2012;12(2):304-9.

13. Su JA, Tsai CS, Hung TH, Chou SY. Change in accuracy of recognizing psychiatric disorders by non-psychiatric physicians: Five-year data from a psychiatric consultation-liaison service. Psychiatry and clinical neurosciences. 2011;65(7):618-23.

14. Atram AR. Comparison between Psychiatrists and Non-Psychiatric Physicians Identifying Psychiatric Symptoms: A Clinical Study. J Psychiatry. 2015; 18:204

15. Dilts SL, Mann N, Dilts JG. Accuracy of referring psychiatric diagnosis on a consultationliaison service. Psychosomatics. 2003;44(5):40711.

16. Al-Huthail YR. Accuracy of referring psychiatric diagnosis. International journal of health sciences. $2008 ; 2(1): 35-8$.

17. Tekkalaki B, Tripathi A, Arya A, Nischal A. A descriptive study of pattern of psychiatric referrals and effect of psychiatric intervention in consultation-liaison set up in a tertiary care center. Indian Journal of Social Psychiatry. 2017;33(2):165-70.

18. Patra P, Divinakumar KJ, Prakash J, Patra B, Chakraborty R. Clinico-psycho-social profile of patients brought under consultation-liaison psychiatry care in a large tertiary care referral hospital. Industrial psychiatry journal. 2017;26(1):24-7.

19. Keertish N, Sathyanarayana MT, Kumar BH, Singh N, Udagave K. Pattern of psychiatric referrals in a tertiary care teaching hospital in southern India. Journal of clinical and diagnostic research: JCDR. 2013;7(8):1689-91.

20. Hartling L, Hamm M, Milne A, et al. Validity and Inter-Rater Reliability Testing of Quality Assessment Instruments [Internet]. Rockville (MD): Agency for Healthcare Research and Quality (US); 2012 Mar. Table 2, Interpretation of Fleiss' kappa (K) (from Landis and Koch 1977) Available from: https://www.ncbi.nlm.nih.gov/books/NBK922 95/table/methods.t2/

21. Jindal RC, Hemrajani DK. A study of psychiatric referrals in a general hospital. Indian journal of psychiatry. $1980 ; 22(1): 108-10$.

22. http://niti.gov.in/content/life-expectancy

23. Gopalan MR, Karunakaran V, Prabhakaran A, Jayakumar KL. Prevalence of psychiatric morbidity among cancer patients-hospital-based, cross-sectional survey. Indian journal of psychiatry. 2016;58(3):275-80. 